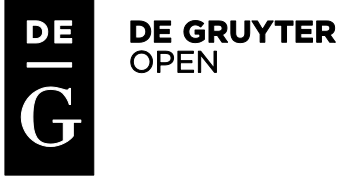

10.1515/topling-2016-0007

\title{
Power in communication: revisiting power studies
}

\author{
Svetlana N. Kucherenko \\ National Research University - Higher School of Economics, Russian Federation
}

\begin{abstract}
This paper revisits a range of theories of power in communication and argues that there has been no methodology able to grasp the multiplicity of power in communication as a concept. As a result, the present scholarship on power in communication is characterized by a multiplicity of approaches that a) use the concept of power as a self-explanatory or vague concept in the analysis of several interactional phenomena; b) draw on a particular approach to power, disregarding multiple workings of power; or c) acknowledge the complexity of power and synthesize various approaches to power.
\end{abstract}

\section{Keywords}

power in communication, theories of power, multiplicity of approaches, discourse, power terms

\section{Introduction}

Although "the notion of power is as old as (social) science itself, and certainly one of the mainstays of scientific debates since the turn of the century" (Davis et al., 1991, p. 7), it is still "another conceptual can of worms" (Thornborrow, 2002, p.5) and keeps stimulating questions around "what it is, where it is located and how it can be analysed" (ibid.). These questions have always been discussed by any social science discipline which deals with social power as one of its key concepts, such as management, politics, economics, psychology, peace studies, conflict studies, game studies, discourse studies and communication studies. In my research I focus only on discourse and communication studies. I review a range of power theories to show that conceptual multiplicity and ambivalence is a hallmark of power studies and needs to be addressed in some way before conducting a proper empirical study of power in interpersonal communication. I first provide reviews of power theories by Russell, Weber, Dahl, Bachrach and Baratz,
Lukes, Blau, Giddens and Foucault to show how they conflict and complement each other in their search for the most illuminating account of power. The choice of the theories is determined by the fact that these theories in particular are used as the theoretical framework in empirical studies of power in communication.

Next, I show how the multiplicity and ambivalence of power as a concept is tackled by Michiel Leezenberg (2002), Thomas Wartenberg (1990) and Miriam Locher (2004). The three of them address multiplicity and ambivalence of power in a new way. Furthermore, I bring up the question of how the multiplicity of conceptualizations of power represent a methodological issue for empirical research of power in communication.

Finally, I provide an outline of a new methodology which could be used to analyse the workings of power in empirical communication studies in particular. 


\section{Multiplicity of conceptualizations of power}

\subsection{Bertrand Russell}

By asserting that power is "the fundamental concept in social science [...] in the same sense in which Energy is the fundamental concept in physics" (Russell, 2004, p.4), Bertrand

Russell introduces into the scholarship the premise that "power can be exercised in any interaction involving two or more interactants" (Locher, 2004, p. 9).

Russell's account of power stands out from a range of similar accounts as he raises the question of various forms of power and introduces a first yet inconsistent classification of various forms of power. He distinguishes between the power of individuals and the power of organizations; hereditary power and acquired power; power by direct physical force, by reward and by influence; and hidden and open power. Russell does not provide a consistent description of the criteria used for the classification; neither does he have a clear argument to show why it is necessary to discuss power in its various forms. In a popular scientific manner, he describes what he holds to be the fact of reality - namely, that there are different forms of power. I regard Russell's intuitive acknowledgment of the complex nature of power as terrain for the further development of the idea of the complexity of power in subsequent studies.

\subsection{Max Weber}

Weber's definition of power as "the probability that one actor within a social relationship will be in a position to carry out his will despite resistance, regardless of the basis on which this probability rests" (Weber, 1978, p.53) has been used in a number of power-in-communication studies so often that it is sometimes referred to as the "classic" or "standard" (Watts, 1990, p.56) definition of power. As Catherine Brennan argues, Weber's ideas about power are much more insightful than they are usually presented as in the commentaries by his interpreters and surpass a "standard" definition of power (Brennan, 1997).

Having done my own critical reading of Weber, I make the following observations:

1. Weber regards power as "sociologically amorphous" (Weber,
1962, p.117) and argues that power is a general term which could be made more precise through such terms as: authority (Weber, 1978), control and domination (Weber, 1962, p. 117).

2. Weber asserts that there are "other forms of power" (Weber, 1978) apart from domination and that the term domination only captures the most general meaning of power in the sense of "imposing one's will upon the behaviour of other persons" (ibid) and "can emerge in the most diverse forms" (ibid).

3. Weber argues that power can be discussed in terms of the economic order through one's class, social order through one's status and political order through one's party (Weber, 1978).

I find Weber's definition quite flexible by virtue of being very general, and this is the reason for its popularity across a number of power-in-communication studies. It allows for various add-ons and interpretations as long as interpretations remain within the limits of the "one-actor-imposes-his-willupon-another-actor regardless-resistance" mechanism.

This mechanism, as John Scott points out, is involved in a whole range of social relations in society (Scott, 2001). Another feature of the Weberian framework is that it implies the idea of power linked to conflict of interests, authority, control, dominance, leadership, influence, asymmetry and force. This also allows the use of the framework in various contexts depending on an analyst's particular goal.

\subsection{Robert Dahl}

Robert Dahl develops his theory of power as a critique of the other theories of power. Thus, he argues that a lack of attention to such "power terms as authority, influence, persuasion, dissuasion, inducement, coercion, compulsion, force and so on" (Dahl, 1995, p. 40) started the analytical tradition of narrowing the meaning of power to one of the power terms. The tradition results from the fact that "the meaning of these words was clear to men of common sense" (Dahl, 1995, p.39). For 
instance, Dahl critiques Weber for explaining power through one of its forms "which he held to be unusually important legitimate power, or authority" (Dahl, 1995, p.40).

In his own turn, Dahl maintains that an analysis of power could hardly accommodate all power terms unless some common denominator is used. He argues that the idea of control is fundamental to all relations covered by power terms and defines such relations as follows: "the behaviours of one or more units (the responsive units, $\mathrm{R}$ ) depend in some circumstances on the behaviours of other units (the controlling units, C)" (Dahl, 1995, p. 40). He argues further on that once the common denominator of control has been identified, the analysis of power should include a discussion of issues common to all power relations, namely, the magnitude, distribution, scope and domain of control. Dahl identifies three major problems with empirical power studies (Dahl, 1995, p. 55): a) a great gap between the concept and operational definitions; b) "different operational measures do not seem to correlate with one another" (ibid); and c) "almost every measure proposed has engendered controversy over its validity" (ibid). As a response to these problems, Dahl attempts to suggest the general methodological principles that power research in particular should follow. If power relations, Dahl maintains, are basically causal relations, then the empirical analysis of power should include the analysis of properties of causation, such as "covariation, temporal sequence and asymmetry" (Dahl, 1995, p. 47). If there are different types of power relations, then the analysis of power should include the specification of particular types of power relations (Dahl, 1995, p. 46). If power relations involve some actual change in the behaviour of responsive units, then the analysis of power should include a discussion of measuring power.

Although Dahl develops his approach to power with the purpose of analysing political power in particular, I assume that his observations about the general principles of power research are applicable to the analysis of power in interpersonal communication as well. I see his major contribution to the discussion of power in the fact that he describes power research as a project methodologically different from other kinds of research by virtue of the complexity of power relations and thus provides the departure points for subsequent empirical studies of power.

\subsection{Peter Bachrach and Morton Baratz}

Peter Bachrach and Morton Baratz are usually referred to as having suggested the two-dimensional view of power, which contrasts with the highly acclaimed threedimensional view of power by Steven Lukes (Locher, 2004, p. 16). It is true that Bachrach and Baratz are the first researchers to consistently argue that power is involved not only in the instances of decision-making but also in those instances where there seems to be no decision-making, where a decision is "a set of actions related to and including the choice of one alternative rather than another" (Bachrach and Baratz, 1970, p.38). Non-decision-making is a "means by which demands for change in the existing allocation of benefits and privileges in the community can be suffocated before they are even voiced" (Bachrach and Baratz, 1970, p.44). In other words, Bachrach and Baratz differentiate between open and hidden power, arguing that hidden power is no less important than open power.

I find Bachrach and Baratz's input much more than a two-faced view of power. In their book Power and Poverty (Bachrach and Baratz, 1970), they introduce five major ideas that are totally overlooked by their commentators and interpreters. First, they show that "power is relational, as opposed to possessive or substantive" (Bachrach and Baratz, 1970, p.21). Second, they describe three conditions necessary for a power relation to exist: "a) there is a conflict over values or course of action between A and B; b) B complies with A's wishes; and c) $B$ does so because he is fearful that A will deprive him of a value or values which he regards more highly than those which would have been achieved by noncompliance" (Bachrach and Baratz, 1970, p.24). Third, they introduce such terms as potential power and latent power and describe the difference between them. Potential power is observed in situations when "the recognition of the possibility of future sanctions results in 'exercise' of power in the present". Latent power is power which is anchored in such instruments as "wealth, high social rank, or a well-stocked military arsenal" (Bachrach 
and Baratz, 1970, p.26). That sort of power is latent until the instrument holder uses these means to introduce some sanctions. Fourth, Bachrach and Baratz draw distinctions between power and related concepts such as authority, influence, manipulation and force (Bachrach and Baratz, 1970, p.37). Fifth, they apply their concepts of decision-making power and non-decision-making power to actual data to show that it is not a mere construct but "susceptible of empirical observation and analysis" (Bachrach and Baratz, 1970, p.16).

\subsection{Steven Lukes}

Steven Lukes's account of power is raised in the scholarship (Locher, 2004) with reference to his three-dimensional view of power, which addresses such issues as the relation between power and structure, power and knowledge, and power and conflict (Lukes, 1974). Critiquing Russell's definition of power as the production of intended effects, Lukes points out that such a conceptualization of power does not allow the answering of such questions as whether the effects should necessarily be intended or whether power is "the actual production of such effects or just the capacity to produce them" (Lukes, 1974, p.2). With regards to Weber's account of power, Lukes argues that it does not properly address the issue of conflict or resistance, although the idea of conflict or resistance is included in Weber's definition. Lukes rejects Dahl's definition of power as the control of behaviour on the grounds that it does not address the problem of measuring the change of behaviour (ibid). In Lukes's view, the problem with Bachrach and Baratz's account of power is that it is still "too committed" to actual behaviour conceptualized in terms of decisions (Lukes, 1974, p.50) and misses out the cases when there is no observable conflict.

Consequently, Lukes proposes his own radical view of power which includes the concept of interest, "A exercises power over $B$ when $A$ affects $B$ in a manner contrary to B's interests" (Lukes, 1974, p.34). He argues that the introduction of the notion of interest in the concept of power allows the capturing of those cases when there is no overt conflict between participants although there is an observable change in the behaviour of $B$.

\subsection{Peter Blau}

Peter Blau is often credited in the scholarship for developing the exchange theory of power (Cromwell and Olson, 1975 , p.19). I see Blau's main contribution to the discussion of power in the fact that he has asserted the inherent connection between power and asymmetry, and power and status. In Blau's view, power is inherently asymmetrical because the exercise of power within the exchange theory of social relations is based on the condition that that there is "one-sided dependence" (Blau, 1967, p.118), with one of the participants of the relation having resources to reward or sanction the other. As Blau argues, power relations emerge when "men have insufficient resources" and "no satisfactory alternatives" to gain access to these resources are available to them; they cannot use coercive force to gain access to the resources, and their need for resources is pressing (Blau, 1967, p.140). Under such conditions, a person who can provide them with the resources they need becomes their superior and can "attain power over them" (ibid). This is how power asymmetries emerge.

Blau regards status to be a sort of capital that an individual can draw and expand upon under proper usage (Blau, 1967, p.132). On the one hand, as Blau maintains, high status is what increases an individual's social attraction to others and secures access to more resources needed to reward or sanction others. On the other hand, high status can be increased by exercising power over others as those individuals are more socially attracted to an individual who can provide them with access to the needed resources. Blau's idea about the link between power and status has turned into an axiomatic assertion that "status is a prerequisite for power" in the subsequent empirical studies of power (Watts, 1991).

\subsection{Michel Foucault}

Michel Foucault introduces into the discussion of power what has become known as the discursive turn (Weatherall, 2002), where the analysis of power has become "a matter of exploring boundaries, breaks and discontinuities, rather than straightforwardly accounting for the material division of goods and opportunities" (Davis et al., 1991, p. 10).

I find the novelty of Foucault's approach to power in the fact that he steps beyond 
the traditional notion of power according to which power emerges when "A in some way affects B" (Lukes, 1974, p.45). For Foucault "power is not a thing, an institution, an aptitude or an object" (Foucault, 1980, p.93) but "something which circulates" or "something which functions in the form of a chain" (Foucault, 1980, p. 98). Power is everywhere. In this sense, power is not always restrictive and dominating, monolithic and hegemonic; it can be creative and cooperative as it presupposes different kinds of relations between participants; it circulates through the entire social body (Caldwell, 2007, p. 775). Nevertheless, power in Foucault's view remains mainly disciplinary in character, which is why subjects are denied agency in his theory; they are free to act only within the limits inflicted on them by the dominating discourse which defines what a particular subject can say about a particular object.

Despite Foucault's heavy focus on the constraining effect of power, he still argues that power is productive and positive, and there is always a possibility for docile bodies to resist the existing constraints. As Foucault claims, "[if] I feel the truth about myself it is in part that I am constituted as a subject across a number of power relations which are exercised over me and which I exercise over others" (Foucault, 1980, p. 39). The implication is that the self is possessed by power, can exercise it over the self and others, and thus can resist the power of others (Caldwell, 2007, p. 775).

It is also worth mentioning that Foucault, however, avoids solid definitions of power unlike his precursors and discusses power in descriptive terms. This seems to me the major reason for the popularity of Foucault's ideas in subsequent studies. It is not the fact that he provides an illuminating answer to all the old questions of power that makes his account different from the others. It is the fact that his ideas of power are very flexible and allow for multiple interpretations.

\subsection{Anthony Giddens}

Giddens's concept of power is developed in his major works: The Constitution of Society: Outline of the Theory of Structuration (1984) and Central Problems in Social Theory (1979). His theory includes the following aspects: a) power is implicated at both the micro-level and macro-level of society; b) power is intrinsic to human agency; c) power is relational, meaning that it includes both asymmetry (resources are distributed asymmetrically among the members of society) and reciprocity in such a way that "the less powerful manage resources in such a way as to exert control over the more powerful in established power relations" (Giddens, 1984 , p. 374); d) power is both productive and constraining; e) power is processual, meaning that it is produced through practices involving domination and subordination while human agents monitor their own behaviour and the behaviour of others in habitual and routine ways by means of "tacit" knowledge (Davis, 1991, pp.70-75).

According to Giddens, the constraining nature of power is realized in the existence of normative components in communication through the continuous process of structuration. Particular interpretative schemes which human agents apply reflexively in communication are constantly produced and reproduced through the structures of signification, domination and legitimation until they become normative components of communication (Haugaard, 2002).

In this section of the paper I have shown how a number of theorists of power develop the concept of power by being engaged in a virtual discussion over the same issues: what is power, how it is exercised, what it is related to, who are the power-holders. They provide various answers to the same questions that stimulate new questions. There is no objective account that can argue why the concept of power as the production of intended effects is conceptually wrong while the concept of power as a relation is adequate. As a result, the picture of power as a concept that social science operates under looks rather heterogeneous and ambivalent. From the overview of the power theories, it becomes evident that:

1. Two clearly different traditions of theorizing power have emerged over time. Within one (Russell, Dahl, Weber) power is viewed as a commodity, within the other (Lukes, Foucault, Giddens) as a relation; 
2. the asymmetrical character of power relations is established as an axiom (Blau, Weber);

3. the complexity of power as a constellation of "power terms" such as authority, control, dominance, influence, persuasion, dissuasion, inducement, coercion, compulsion, force has been recognized as a point of further analysis (Dahl, Bachrach \& Baratz);

4. the dominant meaning of power as restriction or constraint has been proposed (Giddens, Foucault);

5. "the constraining force" of power is regarded as intrinsically connected to its resisting aspect (Giddens);

6. power is regarded as based on open or latent conflict of interests (Bachrach and Baratz, Lukes, Foucault);

7. the difference between latent power and actual power is described; latent power is anchored in various resources that are put to use at some point (Bachrach and Baratz, Lukes);

8. power is believed to be both negative and positive, productive and restraining (Foucault, Giddens);

9. the relation between power and status has been established (Blau, Dahl);

10. freedom of action is regarded as one of the bases for power (Giddens).

The multiplicity of conceptualizations of power and a number of various propositions about the nature of power is the context within which the theory of power has been developing for years. Consequently, when power becomes the subject of empirical studies, such multiplicity poses a methodological issue since there is no criterion to choose between equally logical and well-argued theories of power. In the following section I show how the issue is dealt with in a number of empirical studies of power in communication.

\section{Power-in-communication studies and their inconsistency}

In this section I argue that the conceptual multiplicity of power has a negative effect on empirical studies of power in communication, resulting in the production of partial or inconsistent accounts of power in real interaction.

The section is organized as follows: first I critically discuss the studies that use power as a self-explanatory or intuitive concept, then I move on to the studies that are positioned within a certain theoretical approach to power. The approach to the selection of the papers is partly diachronic, partly thematic. A search for the word "power" either in the title of a paper or in its body has been performed across a collection of linguistic papers and books available in the library of Loughborough University, UK, where the writer of the article completed her PhD studies.

\subsection{Power as a self-explanatory or vague concept}

In this section I develop Spencer-Oatey's claim that "few linguists explicitly discuss the conceptual nature of this parameter [power]" (Spencer-Oatey, 1996, p.22) and show that common to a number of empirical studies of power in communication is the usage of power as a self-explanatory concept. The lack of discussion about the nature of power cannot be put down to the fact that power is not the primary concept in such studies since it is either used in the title of the research, or the analysis of power in relation to some other interactional phenomenon is stated as one of the goals of the research, or power in various combinations is used as a key word.

One group of studies follows the tradition set forth by the research of O'Barr and associates (O'Barr and Atkins, 1988). They observed natural same-gender and cross-gender interaction in American courts with the purpose of describing powerful or powerless language. They argue that the term "women's language" should be abandoned for the term "powerless language" as not only women but also "people with low social power and relatively little previous experience in the courtroom" demonstrate the same linguistic behaviour (O'Barr and Atkins, 1988, p. 378). The term "low social power" appears in the fifth paragraph of their research report (O'Barr and Atkins, 1988, p.378) with no explication whatsoever, and the terms "powerful" and "powerless" are used freely across the report with no explication either, presumably referring to the speech pattern of people with high social power and low 
social power. I find it methodologically unacceptable that the authors leave one of their key concepts unpacked and obscure. Nevertheless, O'Barr and associates are credited in subsequent scholarship for the introduction of the terms "powerful" and "powerless" language (Bradac et al., 1991), which refer to certain "phonological, syntactic and semantic language forms" that "indicate power or lack of power" (Bradac et al., 1991, p.117). Among the indicators of powerless language Bradac et al. name intensifiers, hedges, polite forms, hesitation forms, deictic phrases (Bradac et al., 1991, p.118). Among the indicators of powerful language they name the usage of short replies to questions (Bradac et al., 1981, p.118).

Although Bradac et al. never directly clarify the concept of high or low power that they assume to be a prerequisite for powerful and powerless language, they throw some light on their interpretation of power when they attempt to question the homogeneity of the concepts "powerful" and "powerless" language (Bradac et al., 1991, p.130).

Most subsequent studies, mainly within the field of discursive psychology, operating with the terms "powerful" and "powerless" language, never attempt any conceptual clarification of the terms, presumably treating them as established facts ( $\mathrm{Ng}$ and Bradac, 1993). Some imply that verbal interaction is an index of social power. For example, Holtgraves and his students (Holtgraves and Lasky, 1999; Blankenship and Holtgraves, 2005) analyse the various effects of powerful and powerless language in the act of persuasion to conclude that the impact of powerless or powerful language on persuasion is very complex. In the process of analysis the term "linguistic power" emerges. In Blankenship and Holtgraves (2005), the term "linguistic power" is in use from page 5 onwards, in Holtgaves and Lasky from the title onwards. In both studies the authors do not go further than claiming that linguistic power affects persuasion. The term linguistic power remains obscure across their studies. Is it synonymous with "powerful" language? Is it a direct consequence of social power? What is meant by power in the context of the studies? These questions are never discussed by Holtgraves and his students.

A number of studies that focus on the relations between power and gender demonstrate the same pattern of dealing with the concept of power, or rather not dealing with it in an explicit way. There is some scarce implication as to what a researcher means by "power" while using it as one of the main analytical notions. West and Zimmerman proceed from claims that "power is an important facet of many other social relationships" (West, 1998, p.396) and that "verbal interaction [is] an index of power in familial interaction" (West and Zimmerman, 1998, p.173). Their research yields interesting findings about gender and power. Thus, West finds that "gender can have primacy over status where women physicians are concerned [...] even where other power relations are concerned" (West, 1998, p.409). Implied is the conceptualizing of power through one's social status.

The goal of Kollock et al.'s research is to divorce the effects of sex and gender in the division of conversational labour in crosssex and same-sex pairs (Kollock et al., 1985, p. 36). In their analysis Kollock et al. a) use the terms "power-balanced" and "power-imbalanced" couples (Kollock et al., 1985, p.38); b) assign low or great power to the participants in the study on the basis of who makes the decisions in the couples and talks more (Kollock et al., 1985, p.38); c) identify the powerful and powerless males and females among their participants (Kollock et al., 1985, p.40); d) discuss power dynamics among the participants (Kollock et al., 1985, p.42); and e) conclude that "power differences can create the appearances of sex differences" (Kollock et al., 1985, p.45). It is only implied in the methodological and analytical sections of their research report that they treat power as a sort of influence on decision-making. Not until the discussion section do they make it clear that they refer to "a structural definition of power" (Kollock et al., 1985, p.45).

West and Zimmerman (1983) study interruptions in cross-sex conversations between unacquainted people, and in the very first line of their research report they state that "[the] exercise of power in interactions between women and men is perhaps most effective when it is muted, if not euphemized" (West and Zimmerman, 1983, p.102). It follows then that the exercise of power is one of the foci of their research. However, there is no other clarification of the concept "power" apart 
from the assumption that "the interruption is a device for exercising power and control in conversation" (West and Zimmerman, 1983, p.103). It is implied here that power amounts to control in this research. Other than that, the concept of power is left vague throughout the research paper. Powerrelated terms such as "a power differential" or "doing power" emerge in the discussion section (West and Zimmerman, 1983, p.111) where West and Zimmerman conclude that "power is implicated in what it means to be a man vis-à-vis a woman" (West and Zimmerman, 1983, p.111).

Janie Rees-Miller (2000) examines power in the context of disagreement, which follows from the title of the paper Power, Severity, and Context in Disagreement. Although the author refers to power as one of the factors that could "shed light on the complexity of factors involved in the severity of disagreement" (Rees-Miller, 2000 , p. 1088), stating as one of the goals of the paper "to illustrate the complexity of power" (ibid.,) and devoting a whole section of the paper to argue that in her data in a university setting "the professor has an institutionalized right to disagree with students" (Rees-Miller, 2000, p. 1095), she does not have any findings on the complexity of power apart from claiming that "[some] differences in use of linguistic markers of disagreement can be accounted for by the asymmetrical power relationship between professors and students" (ReesMiller, 2000, p. 1107). At one point in her paper, the author also throws some light on her understanding of power within the context of the research by stating that "the institutionalized power held by professors over students [is] based on greater knowledge, academic status, and age, as well on the professors' responsibility for assigning grades" (Rees-Miller, 2000, p. 1095).

There is another group of studies that do not deal much with the concept of power although the word "power" is mentioned in the title or is used now and then in the body of a paper. The term "power" is stated in the title of the study in, for instance: Nailing Down an Answer: Participation of Power in Trial Talk (Matoesian, 2005) or Discourse, Dominance, and Power Relations: Inequality as Social and Interactional Object (Tileaga, 2006) or as a keyword for the study in The psychological and social dynamics of topic performance in family dinnertime conversations (Abu-Akel, 2002). The term "power" is then randomly brought up throughout the papers, e.g. "the naturalization of power" (Matoesian, 2005, p.740); "coercive power" (Matoesian, 2005, p.747); "an intertextual projection of power" (Matoesian, 2005, p.754); or "sex and gender inequality are a good example of how ethnomethodology has dealt with issues related to power and inequality" (Tileaga, 2006, p.477); "[t]he discursive psychological study of social inequality and notions such as power, dominance and exploitation has incorporated the main features of social constructionism" (Tileaga, 2006, p.480); "unequal relations of power" (Tileaga, 2006, p. 490). And finally, the issue of power is brought about in the concluding section of the research to account for the findings with no explication and no evidence whatsoever. For instance, Abu-Akel claims that the fact that children have to nominate the topic several times before it is acknowledged is attributed to "the power of the parents that they can exercise over their young children" (AbuAkel, 2002, p.1801).

So far, I have argued that there is a pronounced tendency in the scholarship on power in communication to use the concept of power as an intuitively understandable notion that requires no clarification or discussion. The multiplicity of theoretical conceptualizations of power produces the effect of power being a notion whose meaning is evident without further explication, which, in its turn, produces a misleading effect for empirical studies. If power is so evident, it can be used to account for quite a number of phenomena in communication from inequality to interruptions. And the total effect is that power as a notion becomes vague.

\subsection{Power within a particular theoretical approach}

In this section I show that within the multiplicity of theoretical approaches to power the most evident analytical decision is to opt for one of the approaches to power. The studies under analysis differ as to the degree of their acknowledgement of the complexity of power.

The essence of these studies is best expressed by Herve Varenne who claims that "a power analysis of an interaction is not, strictly speaking, an analysis "of the interaction" (Varenne, 1987, p.150) but 
rather an analysis of various communication practices with references to cultural propositions, ideological elements and a lot of other kinds of extraneous knowledge (Varenne, 1987, p.146).

In their respective research projects on power in the work place Holmes and Stubbe (2003) and Vine (2004) start off by acknowledging the complexity of the notion of power. Holmes and Stubbe provide an overview of "many ways of defining power" within various perspectives (Holmes and Stubbe, 2003, p. 3) and tentatively underscore in various interpretations the aspects that they tend to view as central to the meaning of power, namely "the ability to control others and the ability to accomplish one's goals" (Holmes and Stubbe, 2003, p. 3 ); "a coercive and even repressive aspect" (Holmes and Stubbe, 2003, p. 5); "a relational nature" (Holmes and Stubbe, 2003 , p. 4): "the relationship with authority, status and expertise". They also indicate that their position on power is informed by Critical Discourse Analysis in so far as CDA "adopts the perspective of those 'out of power", which is useful in their analysis of power in the work place. Their findings about power in the workplace show that the dynamics of intra-organizational institutional power are similar to those of societal institutional power, "the intrinsic and unquestioned power of the dominant group in a society" (Holmes and Stubbe, 2003, p. 154).

Among the various definitions of power, Bernadette Vine focuses on those that are most relevant to her goal of analysing power relationships in the workplace. In the workplace, Vine argues, people interact on various levels, e.g. as equals, as subordinates, as superiors, and it is most relevant to analyse power in terms of bases of power (Vine, 2004, p.1). French and Raven's classification of bases of power seems most suitable in this case. In general, in Vine's view, the relations in the work place involve that kind of power that is coercive and constraining (Vine, 2004, p.2). She also draws on the compliance-gaining theories that focus on power and status (Yinon and Dovrat,1987; Fontaine and Beerman, 1977; cited in Vine, 2004, pp. 2021). Important for Vine's goal are those results that show that people are likely to comply with requests coming from people with "strong referent power", which are based on rational persuasion and have important and enjoyable content (Vine, 2004, p.21). From Vine's focus on scholarship on the power-status bias, it is clear that she regards power as equal to status. Vine makes her observations about power at work separately for equals, and managers and their staff. In the latter case, she finds that managers use a variety of controlling techniques drawing on their high status in the organization and techniques of minimizing their status to produce cooperation (Vine, 2004, p.199). In the case with equals, Vine finds that "expertise" power is still a salient factor although a number of techniques that mitigate one's status are in use (Vine, 2004, pp.201-218).

I find Holmes and Stubbe's and Vine's research projects good examples of how researchers justify amply their choice of theoretical approach to power prior to data analysis and then inactively engage with the concept throughout their research. Although both Holmes and Stubbe and Vine declare power as one of the foci of their research, their research is not about power. Power emerges as one of the variables having an effect on interaction in the workplace.

In a range of power and gender studies in which power is also treated as one of the variables for gender differences in speech, the classic Weberian definition is quite often used as the theoretical framework (Fishman, 1983; Mulac and Bradac, 1995; Leet-Pellegrini, 1988; DeFrancisco, 1998). For instance, in the introductory section of her paper, Fishman (1983) makes a number of comments about the hierarchical nature of power relations, the co-effect of structural forces and interactional activities in the exercise of power (Fishman, 1983, p.89). Her findings reveal that women "are more actively engaged in insuring interaction than men" (Fishman, 1983, p.98). Although Fishman is rather accurate in her usage of the term "power" and admits that power is complex, her findings say little about power in particular in cross-gender interaction. Power still remains more of a rhetorical device since Fishman never returns to the issue after the introductory section and does not use the concept of power to discuss her findings.

Kathy Davis's research into gender and power in medical interaction really stands out from a number of power and gender studies because she not only justifies her 
choice of Anthony Giddens's theory of power as her theoretical framework but also argues that his theory of power is highly suitable for use in any analysis of power on the following counts: a) it helps link a micro-analysis of power to a macro-analysis; b) it does not treat power as straightforward as in the Weberian theory, nor as constraining as in the Foucauldian theory; c) it combines both structural and individual approaches to power; d) it can be used to understand asymmetrical relations of power in everyday interaction "without having to blame them for structural inequalities" (Davis, 1991, p.83). Thus, Giddens's theory suits best the accomplishment of Davis's goal to "explore how patients could actively and knowledgeably participate in the struggle for power" (Davis, 1991, p.56). Davis's other accomplishment is that she actively works with the concept of power as the object of her analysis rather than using it as a popular academic discourse background. She operationalizes the theoretical concept in terms of power practices involved by the patients in getting the floor, describing a problem, making a point and relinquishing the floor (Davis, 1991, p.201).

\subsection{Power as a complex concept}

In the previous section, I showed that although there are researchers who are well aware of the complexity of power, they still position their research within a particular perspective on power because it might be academically safer, empirically easier or consistent with the dominant tradition of the time. In this section, I focus on those empirical studies that attempt to deal with the complexity of power in their analysis rather than simply acknowledge its complexity at the level of describing their theoretical position. I argue that the more sensitive to various aspects of power researchers are, the more of the analysis of power they do. Consequently, in the studies by Watts (1991) and Thornborrow (2002) power ceases to be a rhetorical device in the title and commences to be the subject of their analysis. Their grounded and detailed analysis of power requires the writing of books to publish results, whereas a less detailed analysis can be reported in the format of the papers analysed in the previous section.

Richard Watts's approach to power in his research of family interaction is the first attempt at a synthesized approach. Richard Watts is sensitive to various conceptualizations of power as he critically discusses them in his overview of power to claim that none of them is suitable to be the sole theoretical approach for his research as each of them misses out some aspect of power that is evident in the other approach. Watts argues that for the purpose of "the analysis of verbal interaction" one needs "a clear, usable notion of power" that includes "the fundamental features underlying the variety of the conceptualizations" (Watts, 1991, p.56). Watts modifies the definitions of power that he has discussed and suggests his own clear and usable definition of power:

An individual A possesses power if $s /$ he has the freedom of action to achieve the goals s/he has set her/himself, regardless of whether or not this involves the potential to impose A's will on others to carry out actions that are in A's interests. (Watts, 1991, p.60)

Watts also explores the relations between power and status in terms of status being pre-requisite to the exercise of power. I find his achievements multifold. First, he attempts to single out a fundamental feature in various definitions of power to produce a synthesized definition; second, he suggests a clear method of measuring power in terms of status points that participants can score in the interaction; third, he carries out the analysis of power on the micro-level in terms of topic development and topic maintenance, and thus makes the notion of power more analytically visible.

In the next few paragraphs I focus on Joanna Thornborrow's study of power in institutional discourse to show that she deals with the complexity of power in a different way in comparison with Watts.

If Watts develops his own definition of power modifying the existing definitions of power and underlying fundamental features of power, Thornborrow does a number of case studies in which she analyses power from various analytical points of view, for instance, as an asymmetry of resources within a police interview, as control over a radio phone-in talk and media interviews with the help of questions and formulations, and as participation management in classroom interaction. 
Underlying Thornborrow's analysis of power is the conceptualization of power as "a set of resources and actions which are available to speakers and which can be used more or less successfully depending on who the speakers are and what kind of speech situations they are in" (Thornborrow, 2002, p.8). What makes this definition different from Watts's one is its empirical bias (Thornborrow, 2002, p.5). Although Thornborrow does a comprehensive review of a number of existing theories of power, she does not synthesize them in order to produce her own definition as Watts does. She rather suggests a less theoretical and more empirically usable definition and pencils the ways of operationalizing power in her research in terms of linguistic and discursive resources. She does a review of the existing scholarship with the purpose of singling out the aspects of power across which she can analyse power in her own research. Thus, from the Foucauldian concept of power she draws the idea of power being actively constructed by the participants (Thornborrow, 2002, p.15). Thornborrow's main achievement seems to be in her attempt to bring power analysis to a more empirical level of analysis.

Thus, both Watts and Thornborrow start to put forward the idea of a synthesized approach to power. While Watts produces a new working definition of power that draws on fundamental features from a number of other definitions, Thornborrow prefers a more empirical approach by analysing power in various contexts across a number of aspects that she also draws from various approaches to power. Nevertheless, their approach to power in communication is not yet fully consistent and seems to call for further development.

\section{Theoretical approaches to power that address its complexity}

In this section, I focus on work by Leezenberg (2002), Wartenberg (1990) and Locher (2004) to show how Leezenberg and Wartenberg reject most dominating assumptions on power to develop a theorization that addresses the plurality of forms of power and how Locher applies the idea of the plurality of forms of power in her empirical research of power in disagreements. I start off with Michiel Leezenberg's approach to theorizing power since he spells out the most general propositions about what a new approach to power should look like. Second, I focus in detail on Thomas Wartenberg's field theory of power to show how he develops his synthesized approach to power by providing new answers to the old questions about power. Finally, I argue that Miriam Locher's research is the most consistent attempt to develop a methodological approach that addresses the complexity of power on an empirical level.

\subsection{Michiel Leezenberg's view of power} Leezenberg's goal is to discuss "what a more analytic and theoretically useful notion of power should look like" (ibid.). It follows then that Leezenberg proceeds from the assumption that the accepted notion of power is not adequate from Leezenberg's point of view.

Leezenberg critically discusses the five theories of power that he values most among a range of other theorizations of power - those by Wolfe, Foucault, Weber, Searle and Bourdieu - to argue that all of them fail to provide an adequate account of power despite their theoretical value.

As a logical conclusion to his critique of the most sophisticated theories of power, Leezenberg claims that "a more systemically elaborated concept of power" is necessary (p.906). Leezenberg is doubtful if it is feasible at all to generate such a concept but he suggests four guidelines as to what this concept should look like. His propositions are as follows: a) "negotiation, struggle and challenge are internal" to power; b) power is "intentional", thus it cannot be considered without "beliefs, goals and aims" of interaction; c) power is more than "the opposition between domination and subordination; d) power can be both positive and negative.

Although Leezenberg has not specifically worked within the theory of power, I argue that he has set the terrain for a new approach to power.

\subsection{Wartenberg's field theory of power}

Wartenberg starts his discussion of power by arguing that the conceptual ambivalence in power studies develops from the fact that social theories of power fail to recognize the difference between two similar yet different concepts: the concept of power-over and the concept of power-to. "It is my claim that, despite the appearances of unity of meaning conveyed by the term 'power', these two different uses of the term have 
fundamentally different meanings, a feature of the term that has not been adequately recognized by social theorists" (Wartenberg, 1990, p.18).

Having identified the faulty assumptions of the previous theorizations of power, Wartenberg sets out to develop "a field theory of power" that treats "an agent's power over another agent as a field within whose effect the subordinate agent acts" (p.71) and that is free of the faulty assumptions of the previous theories. The two main components in his field theory are the concept of a field and the concept of an action-environment.

The term field "has a different type of 'being' than that which is normally attributed to objects and their properties. For this reason, to conceive of power-over on the model of a field is to conceive of it in a more complex fashion, one that allows us to see more clearly its mode of existence" (p.74). Wartenberg illustrates the essence of the term with the help of the metaphor of a magnet. The term "action-environment [...] specifies the structure within which an agent exists as a social actor. The actions that an agent engages in can be specified in terms of the options available to her in her action-environment [...] only if there is a reason for her to follow that course of action in the situation in which she finds herself" (p.80-1). An agent is believed by Wartenberg to be able to assess possible actions, understand and evaluate them. Having justified the introduction of the two new terms, Wartenberg formulates the definition of power-over in the following way "social agent $A$ has power over another social agent $B$ if and only if A strategically constrains B's action-environment" (Wartenberg, 1990, p.85).

In Chapter 5 of his book Wartenberg argues that "power is articulated" (p.91) in the form of force, coercion and influence that differ as to the type of coercion on the subordinate agent (p.92). An exercise of force relies on the physical ability of an agent to keep another agent from doing what she would prefer to do or to get something to happen to the agent that she would prefer did not (p.93).

In the final chapters of his book Wartenberg addresses the problem of the transformative nature of power. In arguing that "the concept of power-over should not be identified with that of domination" (p.183), Wartenberg shows that "there are uses of power-over that do not amount to the domination of the subordinate agent by the dominant one" (ibid.). These are a paternal use of power "when the dominant agent uses his power to benefit an agent who is not fully capable of rational determination of his actions" (ibid.) and a transformative use of power where "the dominant agent's aim is not simply to act for the benefit of the subordinate agent; rather, the dominant agent attempts to exercise his power in such a way that the subordinate agent learns certain skills that undercut the power differential between her and the dominant agent" (p.184). Furthermore, Wartenberg identifies the reason why the transformative nature of power is often missed out in most theories of power. For this goal, he introduces the term "situated power relations" (p.142) by which he means that "the power dyad is itself situated in the context of other social relations through which it is actually constituted as a power relationship" (ibid.). In other words, the power relations between two agents within a particular situation and at a particular time are the product of other social relations of a higher structural level. Wartenberg exemplifies the concept of situated power relations on the basis of the teacher-student relations showing "that the power that a teacher has as a result of grading her students is not simply interventional - that is, something that occurs as a result of actions that a teacher performs; a teacher's power over her students is structural" (p.144) and "one needs to move beyond the classroom itself in order to gain an adequate understanding of the power of a grade, for the teacher's power over the student is constituted by the actions of social agents who are peripheral to the central dyad" (ibid.).

Wartenberg then argues that the transformative nature of power is often overshadowed by the situated power relations, or rather by the inability of social theorists to detect transformative power relations because "situated power relationships are often superposed upon transformative power relationships, so that the dominant agent no longer uses his power over the subordinate agent in order to empower that agent" (p.203). Wartenberg suggests that "social reality needs to be thought about as actually constituted by superposed relationships" (p.213). 
I have focused in so much detail on Wartenberg's theorization of power to show that his theory is truly superior to other theories on a number of counts. First, to develop his theory he examines in great detail around twenty other theories of power to bring to light their weak and strong points. Second, Wartenberg's approach to developing a new theory of power is different from traditional discourse. Wartenberg suggests a new manner of theorizing social reality, for example, by moving from observation to theory rather than from theory to observation as was previously done (p.64). As a result, Wartenberg thinks in categories that surpass the level of individual theories of power and brings to light faulty assumptions typical of strands of theories. Third, Wartenberg manages to provide a general definition of power that is also synthetic because it both incorporates the idea of individual agency (stressed by Giddens), the idea of the structural nature of power (stressed by Foucault, Wolfe, Bourdieu), the idea of various forms of power (introduced by Dahl, Lukes and Foucault), the idea of the intentionality of power (developed by Lukes), and the idea of the dual nature of power as positive and negative (developed by Foucault). Rather than thinking of power as dyadic relations, he introduces the concept of situated relations and thus accommodates both individual agency and structural relations within the concept of power. Given this, Wartenberg's field theory can serve as a basis for a new analytical approach to power that will address its multiplicity.

Given the advantages of Wartenberg's theory (the idea of a synthesized approach to power, the idea of the duality of power, the idea of articulations of power, the idea of the necessity of observations) and its drawbacks (the relations between power-to and power-over remain unclear), Wartenberg's field theory of power generates a number of problems, for example, how the field theory can be applied to actual data analysis, and if other articulations of power are possible, what are the relations between power-to and powerover.

\subsection{Miriam Locher's study of power}

Miriam Locher's study of power is different from other empirical studies of power because Locher does not attempt to choose a superior definition among a range of definitions or suggest a new definition incorporating a number of concepts from other definitions as Watts does (Watts, 1990). Instead, she makes a list of propositions about power that "serve as points of reference when looking for evidence of the exercise of power in real interaction" (Locher, 2004, p.37) and that allow her to "operationalise the concept and identify the exercise of power in naturalistic linguistic data" (Locher, 2004, p.321).

Locher puts forward a list of propositions that serves as "a preliminary checklist for understanding the nature and exercise of power" (p.39). The propositions are as follows:

- Power is (often) expressed through language.

- Power cannot be explained without contextualization.

- Power is relational, dynamic and contestable.

- The interconnectedness of language and society can also be seen in the display of power.

- Freedom of action is needed to exercise power.

- The restriction of an interactant's action-environment often leads to the exercise of power.

- The exercise of power involves a latent conflict and clash of interests, which can be obscured because of a society's ideologies (p. 40).

However, I see Locher's main drawback in being inconsistent with the application of the propositions to her analysis of power. Locher uses her analysis to confirm the propositions. For instance, Chapter 6 of her study is the analysis of power in the context of an argument with the aim "to demonstrate how power is exercised and how it is resisted" (p. 156). The analysis is organized as a close reading of eight units within the argument (emergent networks in Locher's terminology) to describe the topic development, the speech acts used by the participants, the linguistic means employed to achieve their communicative goals and so on. It is a true syntactic, semantic and pragmatic analysis with no reference to the concept "power". At the end of Chapter 6 Locher refers back to the list of the propositions about power from Chapter 2 and with the examples from the close 
reading of the data illustrates the propositions. For instance, she illustrates the proposition "power is expressed through language" by saying that "[d]uring The Argument no physical force was used and the exercise of power was predominantly expressed through language" (p. 207); the proposition "freedom of action is needed to exercise power" is illustrated by the assertion "free interaction was possible for all participants within the frame of the dinner, which is influenced, for example, by the rights and obligations of hosts versus guests" (p. 209); the proposition "the restriction of an interactant's action-environment often leads to the exercise of power" is illustrated by the assertion that some of the participants of the argument controlled the conversation to a great extent by "their mere presence " (p. 211). In Chapter 7 Locher carries out the analysis of formal communication in the same manner: she does the close reading of several emergent units and then refers back to her list of propositions to illustrate each of the propositions with the examples from the data.

Thus, I claim that Locher only partially fulfils her goal of operationalizing power because a) the propositions about power are too general to function as criteria to operationalize power, and b) the analysis is organized so that the data are used to illustrate the relevance of the propositions.

I have shown that Michiel Leezenberg argues for the necessity of developing "a more systemically elaborated concept of power" that incorporates a number of features of the concept discussed within the previous theories, such as the positive and negative aspects of power, the situated and intentional character of power, and its inherent relation with negotiation, struggle and challenge. I have also argued that Thomas Wartenberg's theory can serve as a good basis for a new methodology that addresses the multiplicity of power because it conceptualizes power as a complex phenomenon with a dual nature and with various articulations. I have also shown how Miriam Locher has attempted to carry a multi-dimensional analysis of power in interaction and argued that her study is not fully successful because she applies the propositions to the data post factum.
At this point, I pull together my arguments from the previous sections. In Section $1 \mathrm{I}$ argued that the theory of power is hallmarked by a multiplicity of approaches to power that theorize power from a number of different standpoints and produce conceptual ambivalence. In Section 2 I showed that conceptual ambivalence is also present at the level of empirical studies in the form of partial and inconsistent findings about the workings of power in actual interaction. These two arguments justify the necessity of a new methodological approach to power that could address power in all its multiplicity and operationalize power in a more usable way.

In Section 3 I showed that Wartenberg's theory of power is a potential theoretical basis for a new methodological approach as it theorizes power as a complex issue. Having said that, the main question for the next section is what a new methodology that accommodates the multiplicity of power should look like.

\section{Developing a new methodology: basic principles}

The principles for a new methodology arise from the theoretical and empirical approaches examined in the previous sections. Some of the principles are logically derived from the assumptions of the major theorizations of power discussed in the previous sections, while the others are logically opposed to what has been argued.

\subsection{Multi-dimensional principle}

This principle is based on the idea of power being a multi-faceted phenomenon. In this way I can effectively address the following problems of power a) the duality of power as power-to and power-over; $b$ ) the duality of power as negative power and positive power; c) the multiplicity of articulations of power; d) the multiplicity of the dimensions of power that have their role in the exercise power.

In my research the multi-dimensional principle articulates itself in the form of a multi-dimensional model. The model is conceived of as a virtual construction across two axes and eight dimensions. The number of axes and dimensions is determined by "multiple faces" of power. 


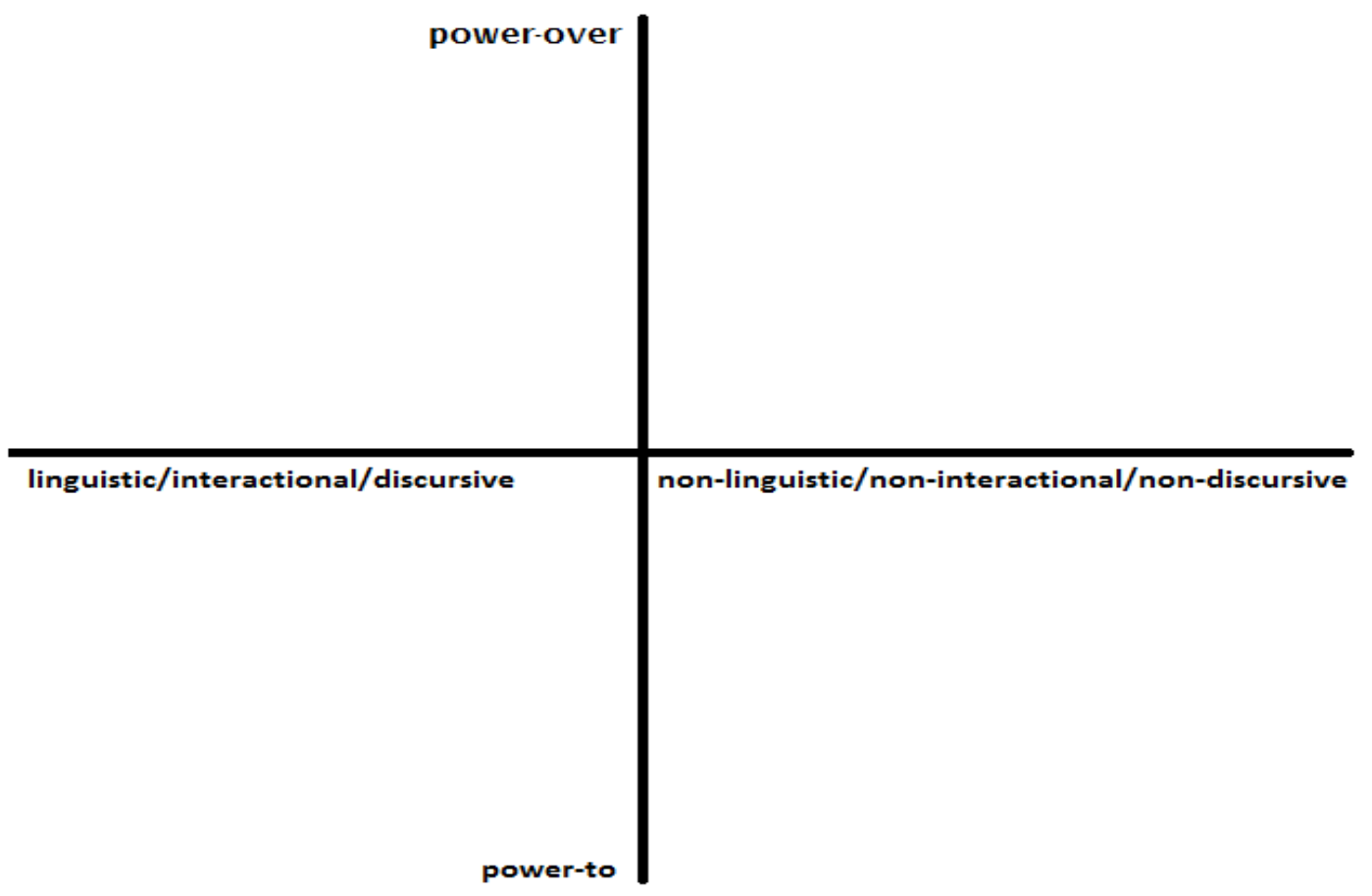

Figure 1: Multi-dimensional model

The actual terms "axes" and "dimensions" are quite arbitrary. What I want to capture with the introduction of these terms is that the theoretical ideas I use for the introduction of the axes reflect more global features of power than those I speak about across the dimensions. The axes which I suggest are the axis of powerto and power-over and the axis of discursive and non-discursive power. The first axis has two focal points: that of power-to and that of power-over. The difference between these two types of power is best captured by Wartenberg, although overtly or intuitively it is also captured by other researchers (see Dahl, Locher, $\mathrm{Ng}$ and Bradac). "Power-to refers to the ability an individual may (temporarily) possess and use, while power-over refers to the hierarchical relationships between individuals which can result in control, dominance, influence, etc." (Locher, 2004, p.11).

The focal points of the second axis are linguistic/interactional/discursive

phenomena and non-linguistic/noninteractional/non-discursive phenomena. As Wartenberg maintains in his research on power, the former can be articulated in various forms including sheer physical force and other non-verbal articulations. In my research I only deal with linguistic/interactional/discursive articulations of power, although I bear in mind that other articulations are possible as well.

The six dimensions that I describe below are situated across the axes in a non-linear way, meaning that they overlap with each. My model includes the following dimensions:

1. power as a latent capacity an individual possesses to achieve their desired goals;

2. power as asymmetry;

3. power as a set of constraints;

4. power as resistance/opposition;

5. power as a conflict;

6. power as production of new meanings.

Each of the dimensions requires a further break-down. For instance, power as a latent capacity can be analysed in terms of such sociolinguistic factors as class, age, education, occupation, gender, wealth, mental and physical abilities, and expertise. I assume that these factors have different value in different cultures and that they define access to various material and virtual resources on which power in the meaning of producing intended effects rests prior to the discursive event.

I suggest operationalizing power as asymmetry in terms of endogenous and 
exogenous asymmetries. These terms are introduced by Linell and Luckmann (1991). According to their theory, there are exogenous and endogenous asymmetries in a dialogue. Endogenous asymmetries such as the roles of speaker and listener, the existence of adjacency pairs, and discursive rights to develop the topic and to allocate the floor are intrinsic to communication. Exogenous asymmetries such as inequivalences of knowledge, social positions, education, personal versions of reality, pre-established institutional and interactional constraints are produced by actual talk (Linell and Luckmann, 1991, p.10). I assume that in achieving their short term-goals the participants produce asymmetrical relations based on endogenous and exogenous asymmetries either by making clear verbal reference to them or by drawing on them in some way. Thus, the technique of analysing the asymmetrical relations of power in terms of endogenous and exogenous asymmetries consists of identifying the instances where the participants demonstrate unequal access to resources.

Power-as-conflict may be operationalized in terms of the action-opposition units that are constructed in interaction being partially predetermined by some sociolinguistic factors such as opposing goals, stakes, outcomes and resources.

The development of analytical tools for each of the dimensions is still in progress.

\subsection{Power-language relationship principle}

That power is articulated in language is another tenet of the contemporary scholarship on power. I use the thesis of the power-language relationship as the second basic principle of my methodology to mean that a) some linguistic forms tend to reveal the exercise of power; $b$ ) language reveals power at all levels of interaction, such as separate linguistic forms, phrases, adjacency pairs, utterances and discourse; c) a bottom-top approach is most effective in the analysis of power in communication. Since the principle is too general in the form "power is articulated in language", in my research I apply it in a narrow articulated form - the form of the triangulation principle (Wodak, 2001).

The principle consists of approaching data in terms of four levels of analysis: a) the immediate language; b) the intertextual and interdiscursive relationship between utterances; c) the extralinguistic and institutional frames of a specific communicative situation; d) the broader socio-political and historical contexts (Wodak, 2001). This principle allows reconciliation between a micro-level and a macro-level of analysis, the combination of various analytical methods, "double- (or triple-) checking of results" (Leeuwen, 2005, p.6).

\subsection{Power-in-context principle}

When Leezenberg proposes the guidelines as to what a more elaborated concept of power should look like, he points out that power "cannot be characterized in isolation" from the aims, beliefs and intentions involved in a particular act of interaction (Leezenberg, 2002, p.906). In other words, Leezenberg puts forward an argument of a contextual sensitivity of power. Thornborrow makes the contextual sensitivity of power one of the leading principles of her analytical approach and sees this aspect as part of her definition of power (Thornborrow, 2002, p.8). She assumes that regarding power as a contextually sensitive phenomenon allows her to focus on the minute details of the discursive situations in which the interaction takes place and to show that power is accomplished at a certain time and in a certain space.

\subsection{Universal applicability principle}

This principle seems to contradict the previous principle of the contextual sensitivity of power as this principle declares that the methodology can be applied to any kind of data emanating from a range of various cultures and types of discourse. However, I regard it as a logical extension of the previous principle. As I showed in the previous section, the principle of the contextual sensitivity of power declares the necessity to pay attention to the goals and details of the type of discourse in which the interaction takes place. If I limit my methodology to the context of broadcast talk, for example, then my methodology becomes genre-biased. Since my methodology is aimed at the analysis of power, which is a multidimensional and complex phenomenon, the methodology of power cannot be genrebiased as it will contradict the essence of its analytical subject. This is why it is necessary 
to test the methodology using data from various types of context encompassing all possible discourses of communication across a culture, for example, interpersonal communication, communication at work, broadcast communication

\section{Conclusion}

In this paper I argued that the present scholarship on power is characterized by a multiplicity of approaches, which determines the methodological choices researchers of power have to make in their studies. These choices are: a) the use of the concept of power as a self-explanatory or vague concept in the analysis of some interactional phenomena with the effect that power remains more of a rhetorical device; b) a single particular approach to power consistent with the purpose of research in the analysis of some aspect of power; c) the acknowledgement of the complexity of power. The multiplicity of theoretical approaches to power justifies the need for a new methodological approach which could address power in all its multiplicity and operationalize power in a more usable way. The basic principles of the new methodology were described in Section 4 of the paper.

\section{References}

ABU-AKEL, A., 2002. The psychological and social dynamics of topic performance in family dinnertime conversations. Journal of Pragmatics, vol. 34, no. 12, pp. $1787-1806$.

BACHRACH, P. and BARATZ, M., 1970. Power and poverty: theory and practice. New York: Oxford University Press.

BLANKENSHIP, K. and HOLTGRAVES, TH., 2005. The role of different markers of linguistic powerlessness in persuasion. Journal of Language and Social Psychology, vol. 24, no. 1, pp. 3 $-24$.

BLAU, P., 1967. Exchange and power in social life. New York, N.Y.: Wiley.

BRADAC, J., BUSCH, J. and GIBBONS, P., 1991. Powerful and powerless language: consequences for persuasion, impression formation, and cognitive response. Journal of Language and Social Psychology, vol. 10, no. 2, pp. $115-133$.

BRENNAN, C., 1997. Max Weber on power and social stratification: an interpretation and critique. Aldershot: Ashgate.

CALDWELL, R., 2007. Agency and change: Re-evaluating Foucault's legacy. Organization, vol. 14, no. 6, pp. $769-791$.

CROMWELL, R. and OLSON, D., 1975. Power in families. Beverly Hills, Calif.: Sage Publications. DAHL, R., 1997. From authoritarianism to democracy via socioeconomic development. Oslo: Department of Sociology, University of Oslo.

DAVIS, K., LEIJENAAR, M. and OLDERSMA, J., 1991. The gender of power. London; Newbury Park: Sage Publications.

DEFRANCISCO, V., 1998. The sounds of silence: How men silence women in marital relations. In: J. Coates, ed. Language and gender: A reader. Oxford: Blackwell Publishers Ltd., pp. 176 184.

FAIRCLOUGH, N., 1989. Language and power. London: Longman.

FISHMAN, P., 1978. Interaction: The work women do. Social Problems, vol. 25, pp. 397 - 406. FOUCAULT, M. and GORDON, C., 1980. Power/knowledge: selected interviews and other writings 1972-1977. New York: Pantheon Books.

GIDDENS, A., 1979. Central problems in social theory: action, structure, and contradiction in social analysis. Berkeley: University of California Press.

GIDDENS, A., 1984. The constitution of society: outline of the theory of structuration. Berkeley: University of California Press.

GIDDENS, A., 1988. Social theory and modern sociology. Cambridge: Polity Press.

HAUGAARD, M., 2002. Power: a reader. Manchester, UK: Manchester University Press.

HOLMES, J. and STUBBE, M., 2003. Power and politeness in the workplace: a sociolinguistic analysis of talk at work. London: Longman.

HOLTGRAVES, TH. and LASKY, B., 1999. Linguistic power and persuasion. Journal of Language and Social Psychology, vol. 18, no. 2, pp. $196-205$.

KOLLOCK, P., BLUMSTEIN, PH. and SCHWARTZ, P., 1985. Sex and power in interaction: Conversational privileges and duties. American Sociological Review, vol. 56, no. 1, pp. 34 46. 
LEET-PELLEGRINI, H., 1980. Conversational dominance as a function of gender and expertise. In H. Giles, P. Robinson and P. Smith, eds. Language and social psychological perspectives. New York: Pergamon.

LEEUWEN, T., 2005. Three models of interdisciplinarity. In: R. Wodak and P. Chilton, eds., A new agenda in critical discourse analysis. Amsterdam/Philadelphia: John Benjamins Publishing Company, pp.3 - 18.

LEEZENBERG, M., 2002. Power in communication: Implications for semantics-pragmatics interface. Journal of Pragmatics, vol. 34, no. 7, pp. 893 - 908.

LINELL, P. and LUCKMANN, TH., 1991. Asymmetries in dialogue: some conceptual preliminaries. In: I. Markova and K. Foppa, eds., Asymmetries in dialogue. New York: Harvester Weatsheaf, pp.1 - 20.

LOCHER, M., 2004. Power and politeness in action: disagreements in oral communication. Berlin; New York: M. de Gruyter.

LUKES, S., 1974. Power: a radical view. London and New York: Macmillan.

MADSEN, L., 2003. Linguistic power wielding and manipulation strategies in group conversations between Turkish-Danish children. In: J. N. Jørgensen, A. Dahl and P. Svenoniu, eds. Proceedings of the 19th Scandinavian Conference of Linguistics, vol. 31 : Bilingualism, pp. 780-795.

MATOESIAN, G., 2005. Nailing down an answer: Participation of power in trial talk. Discourse Studies, vol. 7, no. 6, pp. 733 - 759.

MULAC, A. and BRADAC, J., 1995. Women's styles in problem solving interaction: Powerless, or simply feminine. In: P. Kalbfleisch and M. Cody, eds. Gender, power, and communication in human relationships. New Jersey: Lawrence Erlbaum Associates Publishers, Hillsade, pp. 83 105.

NG, S. and BRADAC, J., 1993. Power in language: verbal communication and social influence. Newbury Park: Sage Publications.

O'BARR, W. and ATKINS, B., 1998. Women's language or powerless language. In: J. Coates, ed. Language and gender: A reader. Oxford: Blackwell Publishers Ltd, pp. 377 - 388.

REES-MILLER, J., 2000. Power, severity, and context in disagreement. Journal of Pragmatics, vol. 32, no. 8, pp. $1087-1111$.

RUSSELL, B., 2004. Power: a new social analysis. London and New York: Routledge.

SCOTT, J., 2001. Power: Key concepts. Cambridge: Polity Press.

SPENCER-OATEY, H., 1996. Reconsidering power and distance. Journal of Pragmatics, vol. 26, no. 1, pp. 1-24.

THORNBORROW, J., 2002. Power talk: Language and interaction in institutional discourse. London: Longman.

TILEAGA, C., 2006. Discourse, dominance, and power relations: Inequality as social and interactional object. Ethnicities, vol. 6, no. 5, pp. $476-497$.

VARENNE, H., 1987. Analytical ambiguities in the communication of familial power. In: L. Kedar, ed. Power through discourse. Norwood, NJ: Ablex Publishing, pp. $129-151$.

VINE, B., 2004, Getting things done at work: the discourse of power in workplace interaction. Amsterdam: John Benjamins Publishing.

WARTENBERG, Th., 1990. The forms of power: from domination to transformation. Philadelphia: Temple University Press.

WATTS, R., 1991. Power in family discourse. Berlin and New York: Mouton de Gruyter.

WEATHERALL, A., 2002. Gender, language and discourse. Hove: Routledge.

WEBER, M., 1962. Basic concepts in sociology. New York: Philosophical Library.

WEBER, M. and RUNCIMAN, W., 1978. Max Weber: selections in translation. Cambridge: Cambridge University Press.

WEST, C. and ZIMMERMAN D., 1983. Small insults: A study of interruptions in cross-sex conversations between unacquainted persons. In: B. Thorne, Ch. Kramarae and N. Henley, eds. Language, gender and society. MA: Newbury House, Rowley, pp. $103-117$.

WEST, C. and ZIMMERMAN, D., 1998. Conversational dominance in mixed talk. In: J. Coates, ed. Language and gender: A reader. Oxford: Blackwell Publishers Ltd., pp. $165-175$.

WEST, C., 1998. When doctor is a 'Lady': Power, status and gender in physician-patient encounters. In: J. Coates, ed. Language and gender: A reader. Oxford: Blackwell Publishers Ltd., pp. $396-417$. 
WODAK, R. and MEYER.M., 2001. Methods of critical discourse analysis. Thousand Oaks, California: Sage Publications, pp.1 - 13.

\section{Author's address and contact details}

Svetlana N. Kucherenko, MA

Department of Foreign Languages

National Research University - Higher School of Economics, Kantemirovskay Str., 3

Saint-Petersburg

Russian Federation

E-mail: skucherenko@hse.ru 